\title{
A Systematic Approach to Find a Professional Audiology Clinic: Patient-Based Information
}

\author{
Gungu Kim ${ }^{1}$, Gibbeum $\mathrm{Kim}^{1}$, Wondo $\mathrm{Na}^{1}$, and Woojae $\mathrm{Han}^{2}$ \\ 1Department of Speech Pathology and Audiology, Hallym University Graduate School, Chuncheon, \\ ${ }^{2}$ Division of Speech Pathology and Audiology, Research Institute of Audiology and Speech Pathology, College of Natural Science, \\ Hallym University, Chuncheon, Korea
}

Received May 10, 2016

Revised June 9, 2016

Accepted June 27, 2016

\section{Address for correspondence Woojae Han, $\mathrm{PhD}$ \\ Division of Speech Pathology and \\ Audiology, Hallym University, \\ 1 Hallimdaehak-gil, \\ Chuncheon 24252, Korea \\ Tel +82-33-248-2216 \\ Fax +82-33-256-3420 \\ E-mail woojaehan@hallym.ac.kr}

This brief communication introduced a systematic way to find a professional audiology clinic developed for patients and professionals by the American Academy of Audiology, American Speech-Language-Hearing Association, and Healthy Hearing. Patients can access each organization's website to find professionals and/or clinics based on criteria such as location, hours, special areas, types of service, reviews and rating by previous patients, and kinds of insurance accepted. Such a system may protect the patients from information overload, guarantee accurate information, and help them find themselves professional audiologists who can assist them. We expect professional organizations to adopt this system as soon as possible and link hearing-impaired patients with professional audiologists in Korea.

J Audiol Otol 2016;20(2):114-119

KEY WORDS: Audiology clinic · Patient-based information · Hearing aids . American academy of audiology · American speech-language-hearing association · Healthy hearing.

\section{Introduction}

According to the World Health Organization (WHO), approximately $5 \%$ of the world population or 365 million people has either moderate or severe hearing loss of either congenital or acquired etiology [1]. In Korea, some 300,000 people are believed to have some hearing loss, which is the second highest of 15 disabilities [2]. Recently, health care professionals are most concerned about noise-induced and age-related hearing loss. WHO reported that nearly 1.1 billion teens and young adults between 12 and 35 years of age are exposed to excessive noise through their personal listening devices [3] and by riding off-road vehicles, motorboats and sporting airplanes [4]. Such activities can result in having irreversible and permanent hearing loss [5] and also incur that middle-aged people are vulnerable to earlier age-related hear-

This is an Open Access article distributed under the terms of the Creative Commons Attribution Non-Commercial License (http://creativecommons.org/licenses/by-nc/3.0/) which permits unrestricted non-commercial use, distribution, and reproduction in any medium, provided the original work is properly cited. ing loss [6]. Furthermore, the number of elderly people with hearing loss is rapidly increasing as the population ages. Statistics Korea published a prediction index in which the percentages of people aged 65 years and older are $13.1 \%, 24.3 \%$, and $40.1 \%$ of the total population in 2015,2030 , and 2060 , respectively [7]. In short, given that hearing loss is the thirdmost chronic condition of the elderly people and since $40 \%$ of the population older than 75 years have hearing loss, the increasing number of people with hearing impairment needs more professional services in the near future.

Nowadays, screening all newborns for hearing loss and offering aural rehabilitation as soon as indicated are supported by professional organizations and governments worldwide $[8,9]$. The Korean Ministry of Health and Welfare provides financial support for early detection of hearing loss in highrisk babies and extends its support to all newborns [10]. In contrast to systematic medical management for infants and young children with congenital hearing loss, there is a no comparable system for Korea's hearing-impaired adults and elderly. Fortunately, the Korean government now reimburses a portion of patients' hearing aid costs and will provide free hearing 
tests to lower-income families in 2017 [11]. As results of this change in the welfare policy, we might expect more people with hearing impairments to purchase hearing aids and to consult audiologists.

However, it is not easy for people who suspect hearing loss to contact a professional audiologist [12]. Too much information and too many online advertisements can be confusing. Table 1 shows that the searches for "hearing aid" on the most popular websites in Korea, NAVER Corporation (www.naver.com) and DAUM Corporation (www.daum.net) turned up 177,069 and 131,000 hits, respectively. When "hearing-impaired" and "hearing loss" were searched, NAVER showed 164,410 and 49,404 documents and DAUM revealed 115,000 and 18,000. For the word of "tinnitus," 243,119 and 227,000 advertisements were displayed on NAVER and DAUM. Thus, these general online searching systems cannot protect the patients from inaccurate information and have a limitation of helping them find professional audiologists who can help them [12]. Furthermore, there is a lack of authentic audiology websites in Korea. The website of Audiological Testing Service which is one of representative professional organizations only provides a few lists of registered audiologists in Korea (www.audiologykorea.or.kr). The information that it contains is limited to the name of members (audiologists), state (location), title of hearing center, phone number, and email address. Also, two hearing aid companies, Starkey Korea (http://www.starkey.co.kr/) and Phonak Korea (http:// www.phonak.co.kr/home/index.php? src=naver_br\&kw= 00000B) display a list of centers. In sum, none of them offer the information that patients most need to know and the websites are not user-friendly. Again, to find an audiology clinic and the best audiologists, a hearing-impaired person in Korea needs the kind of systematic method that is found in developed countries. Organizations such as the American Academy of Audiology and the American Speech-LanguageHearing Association list certified professionals who have undergone continuing education. This paper will suggest a systematic way to find a professional audiology clinic based on the recommendations of several authentic audiology organizations and will compare them from a patient's perspective.

Table 1. Number of documents when finding words related to hearing in two portal sites

\begin{tabular}{lrr}
\hline \multicolumn{1}{c}{ Word list } & NAVER & \multicolumn{1}{c}{ DAUM } \\
\hline Hearing aids & 177,069 & 131,000 \\
Hearing impaired & 164,410 & 115,000 \\
Hearing loss & 49,404 & 18,000 \\
Tinnitus & 243,119 & 227,000 \\
\hline
\end{tabular}

Search date at January $25^{\text {th }}, 2016$
For the best selecting audiology organization, number of members, credential certificates, authority, representativeness, expertise, and independence were considered, resulting in including three audiology organizations, i.e., American Academy of Audiology, American Speech-Language-Hearing Association, Healthy Hearing, in the United States for the current report.

\section{American Academy of Audiology}

The American Academy of Audiology (AAA) was founded by Dr. James Jerger in 1988. The AAA is an independent and freestanding national organization run for clinical and research audiologists. It is uniquely sensitive to the professional issues and concerns affecting all audiologists. Although the first national convention of the Academy was attended by about 600 people in 1,989, the 13th Annual Convention in 2001 hosted more than 7,300. The AAA is the world's largest professional organization for the audiologists. Its more than 12,000 active members are dedicated to providing high-quality hearing care services through professional development, education, research, and public awareness of hearing and balance disorders.

In addition, AAA has offered patients with hearing loss an opportunity to meet certified audiologists. When visitors go to AAA website (http://www.audiology.org/), they can find a large symbol on the right side: "Find an Audiologist" (Fig. 1A). After clicking the symbol, they can filter audiologists by location (i.e., city, zip code, country) and specialty (Fig. 1B). In the specialty for the professionals, the patients select from among lists, such as auditory brainstem response (ABR), electronystagmography, hearing aid dispensing, intraoperative monitoring, vestibular testing, hearing conservation, cochlear implants, auditory processing, tinnitus, and newborn hearing screening. By clicking either "diagnostic" (Fig. 1C) or "rehabilitation" (Fig, 1D), they can choose specialists in pediatric and/or adult hearing loss. For example, if the patients want to be physiologic tested and to have ABR examination in Los Angeles, they click LA and a check box for ABR and then get a list of 20 certified professionals (Fig. 1E). As the first audiologist listed, Kimberly Allred, AuD, FAAA was found. On the next page, the patient can continue to see her full name and certifications, the name, address, and phone number of her clinic, and a list of her specialties (Fig. 1F). This information can be printed out. The last line of the address information is linked to MapQuest, the most popular online mapping service in the United States. Through the MapQuest, the patients can find the clinic (Fig. 1G) or get directions to it from their current location (Fig. 1H, I). 

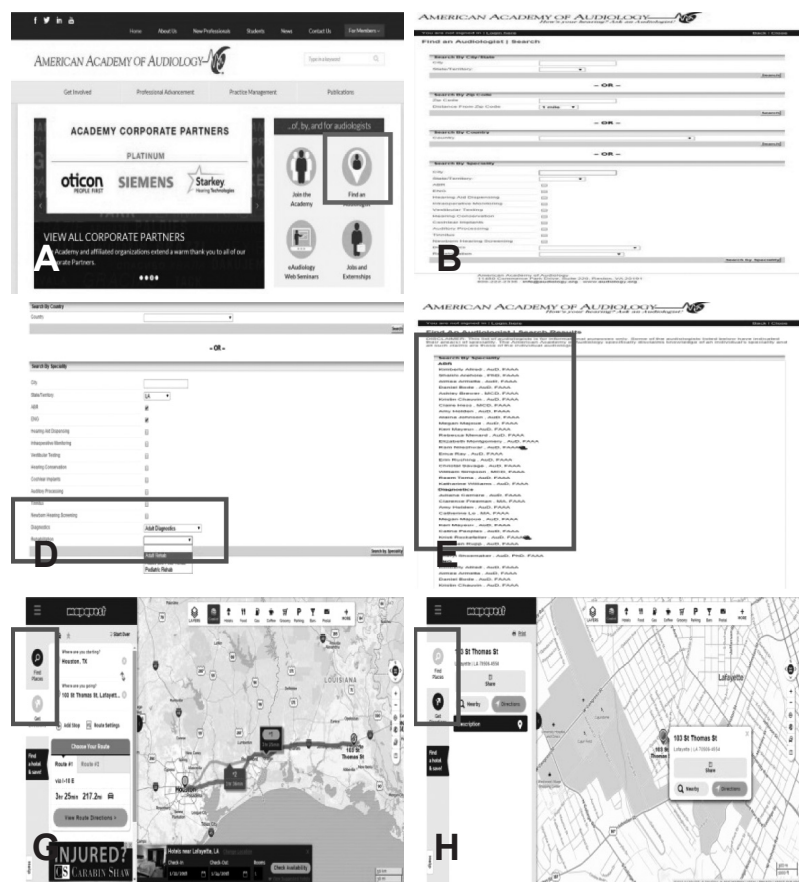

\section{American Speech-Language-Hearing Association}

Since having an informal meeting of 25 members in 1925, the American Speech-Language-Hearing Association (ASHA) has continued to educate and manage speech-language pathologists, audiologists, and speech and hearing scientists. ASHA is defined as a professional, credentialing, and scientific organization for these professions, while leading the development of national standards for clinical speech-language pathologists and audiologists and certifying related professionals. One difference between ASHA and AAA organizations is the characteristics of its members. ASHA is open to both speech-language pathologists and audiologists; AAA is limited to certified audiologists. ASHA has empowered and supported its members academically and clinically. It has grown exponentially and now has 186,000 professionals worldwide.

When patients need a specialist in communication disorders, they can go to the ASHA website (http://www.asha.org/) (Fig. 2A). A button in the middle of web page says "Find a Professional" (Fig. 2B). Clicking the button leads to the next page where there is a list of 15,000 certified audiologists and speech-language pathologists (Fig. 2C). Below "Find a Professional" is "For Certified Professionals" where professionals can add or to update their profile. In the ASHA ProFind page, the patients type in the search terms (e.g., specialty, city, language) in the search engine (Fig. 2D). For example, by typing "hearing orientation" into the search engine, they find

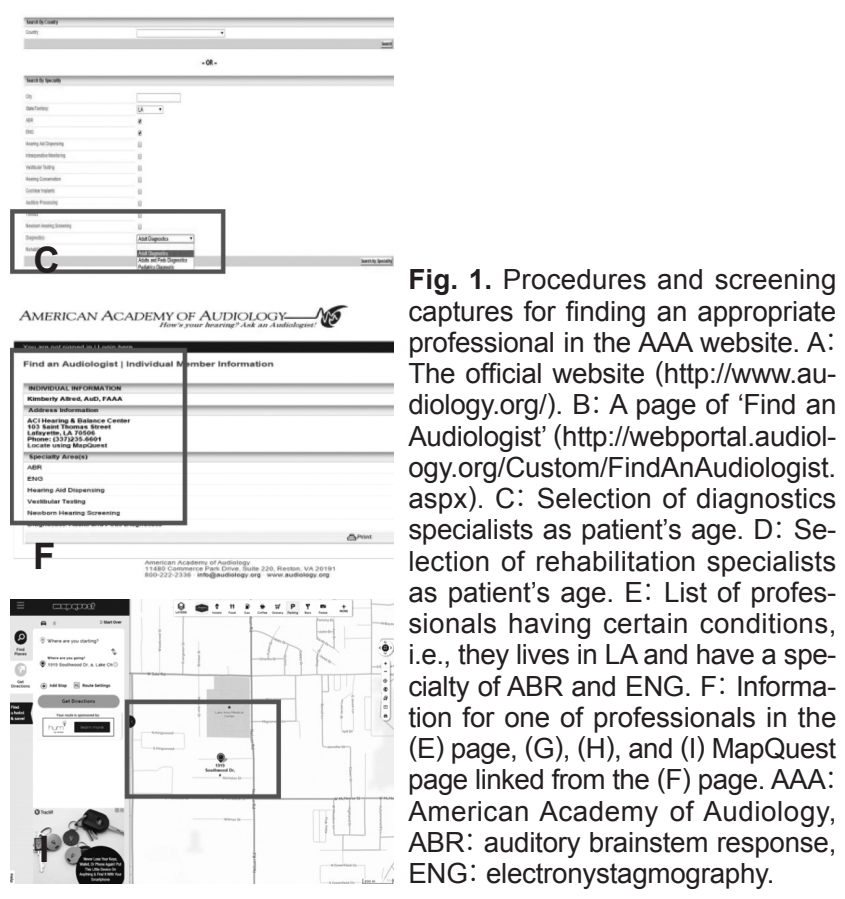

a list of information by type (892 audiologists and 107 speech-language pathologists), ages treated (0-6 months, 7 months -2 years, $3-5$ years, $6-11$ years, $12-17$ years, $18-$ 64 years, 65-74 years, 75 years and older), areas of expertise, bilingual service provider, and city (Fig. 2E). On the left side of the page, they can click a check box 18-64 years in the ages treated and hearing aid orientation in the areas of expertise, then get 852 certified professionals on the right side. Among them, for instance, let's select Jackie J Lee, CCC-A (Fig. 2F). On the next page, the patients see her certification status, area of certification, and when it expires, and contact information (Fig. 2G). The page also gives her areas of expertise, ages treated, education and employment history, and whether or not she is a bilingual service provider (Fig. 2H).

\section{Healthy Hearing}

The Healthy Hearing $(\mathrm{HH})$ website was created to educate people with hearing loss and their families and to encourage them to find help. HH has a president, director, customer support manager, senior developer, assistant editor, and staff writer in its team, and provides news and articles, especially for the USA and Canada. Although HH does not sell any products or run any hearing aid clinics or provide medical advice, it informs the public about hearing loss and hearing aids in layman's language. HH wants to be a leading information portal where patients can receive professional and useful content.

Like the other two websites, HH clearly displays "Find a Professional" on its main page (http://www.healthyhearing. 
$\mathrm{com} /$ ). A visitor can type in a city, state, or zip code or click an area on a map of the United States (Fig. 3A). For example, by clicking Illinois (Fig. 3B) patients see an alphabetical list of cities in that state (Fig. 3C). By selecting Urbana, the patients are taken to the "Hearing aids in Urbana, IL" page (Fig. 3D). In that page, they also refine their search result us-

Fig. 2. Procedures and screening captures for finding an appropriate professional in the ASHA website. A: The official website (http://www. asha.org/). B, C: A page of 'Find a Professional' (http://www.asha.org/ profind/). D: Search engine for typing in the search word which the patients want to find. E: List of professionals having certain conditions, i.e., provide type, ages treated, areas of expertise, bilingual service provider, and city. F: Given professional of the list, $(\mathrm{G})$ and $(\mathrm{H})$ her professional information. I: Explanation of ASHA certification. ASHA: American Speech-Language-Hearing Association.
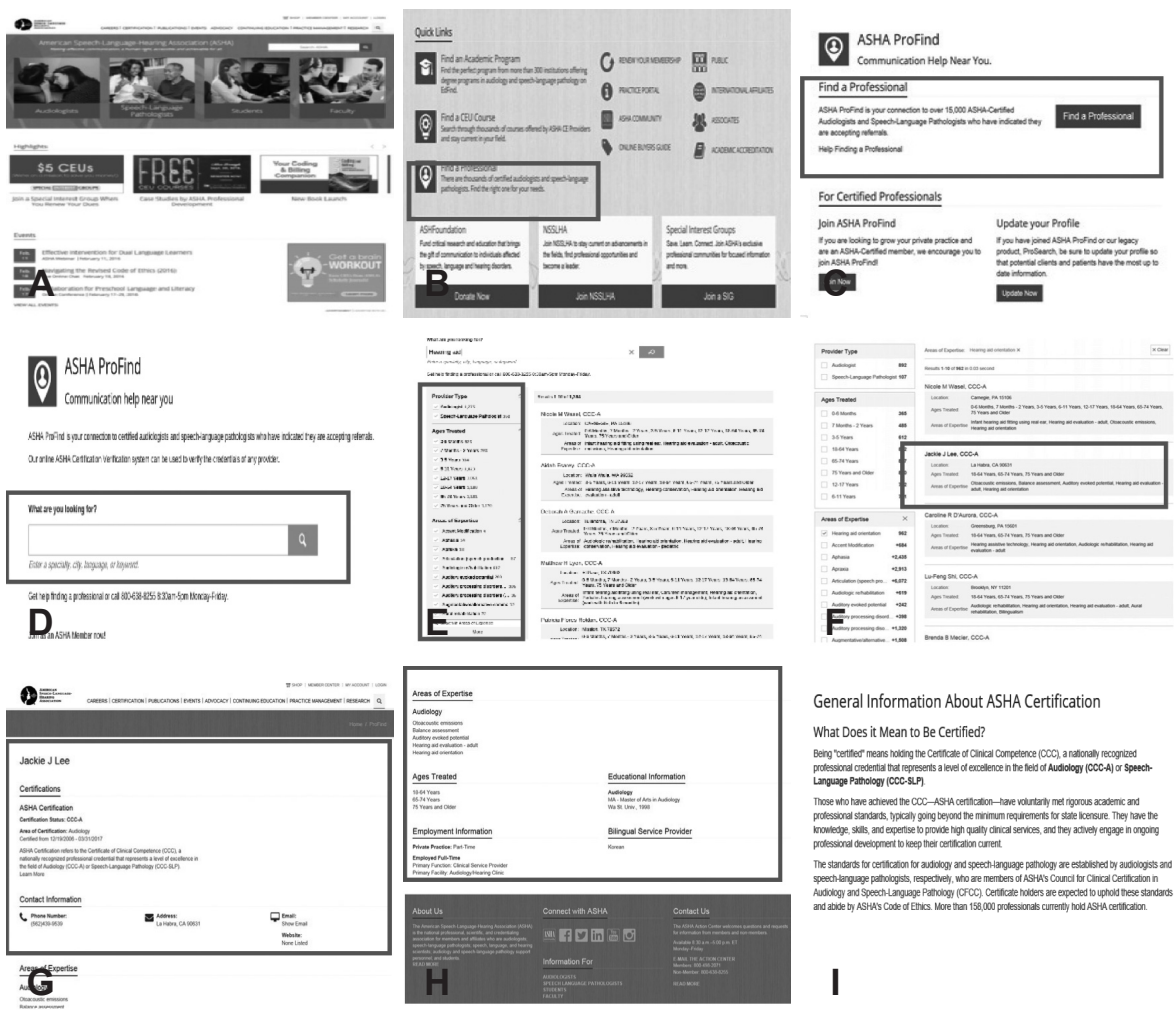

General Information About ASHA Certification

What Does it Mean to Be Certified?

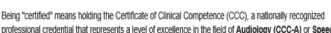

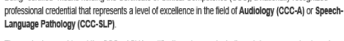

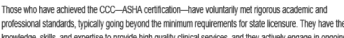

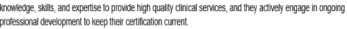

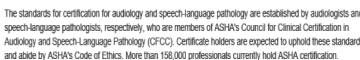

Fig. 3. Procedures and screening captures for finding an appropriate professional in the Healthy Hearing website. A, B: The official website (http://www.healthyhearing.com/) C: List of cities in the selected state. D: Finding results having 15 audiology clinics and refine se-arch options. E: List of hearing clinics. F-l: Information of selected clinic including name, phone number, address, list of clinic staff, operating hours, patients' reviews and a list of clinic service.
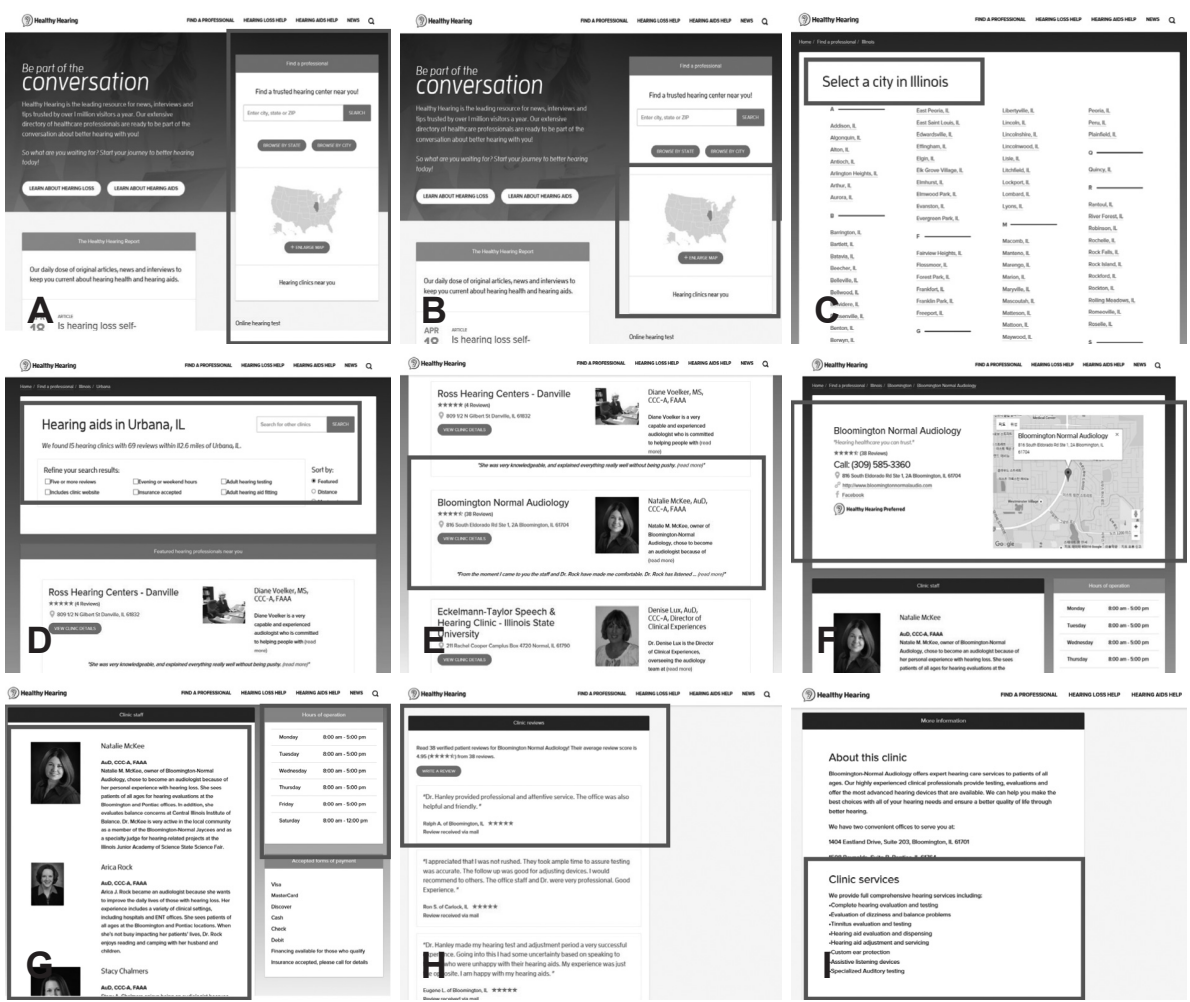
ing six check boxes: five or more reviews, clinic website, evening or weekend hours, insurance accepted, adult hearing testing, and adult hearing aid fitting. They can also select one of the hearing centers from the list on that page (Fig. 3E). After clicking the center, they read its information: the name of the center, its phone number, address, and location on Google Maps (Fig. 3F). Underneath, are the descriptions of the clinic staff. The right side gives hours of operation (Fig. 3G). At the bottom of the page, are clinic reviews by previous patients (Fig. 3H) and a list of services provided by the clinic (Fig. 3I).

\section{Discussion}

One-fourth of people with hearing loss who own hearing aids claim that the recognition of their disorder was higher than any other hearing loss groups $[12,13]$. Among them, new hearing aid users might express high satisfaction of their hearing aid when they meet the professional audiologist and have excellent counseling and rehabilitation [14]. For example, new users depend on orientation books of hearing aid and were more likely to attend an aural rehabilitation group than the experienced users who are more satisfied with their hearing aids. On the other hand, approximately $13 \%$ of the new users never use their hearing aids. Moreover, one in four new users wear their hearing aids less than two hours a day although experts agree that the users who wear their hearing aids at least four hours a day tend to be more successful [12]. This rate of users having negative perception of their hearing aids is a serious problem that cannot be ignored. That is, whether or not new hearing aid users succeed depends on the availability of good audiologists. Unfortunately, new users do not always know how to choose the right audiologist. This brief paper presents a way to find a professional audiology clinic though three professional organizations in the United States. Although those organizations are similar, there are differences in the patient-based information that they provide (Table 2). Visual explanation lets the patients locate a clinic in the HH website, and AAA help the patients find the most suitable professionals by choosing very detailed information. ASHA gives the number of professionals in each category and allows professionals to maintain their own profiles (Fig. 2I). By emulating these organizations, we can offer more useful information for the hearing-impaired people in Korea.

Kochkin, et al. [12] insisted that professional quality of the hearing aids dispensed and audiological counseling have not kept pace with technological improvements in hearing aids during the past decade. It means that little progress has been made in increasing the proportion of patients who are "satisfied" or "very satisfied" with their hearing aids. It is estimated that the number of patients who do not wear their hearing aids increased from $11.7 \%$ to $17.9 \%$ accounting for more than 1 million patients in the United States [12]. The key reasons are that they do not work and that they are uncomfortable. Unfortunately, those problems are easily solved by audiologists. Many experts argued that there is great variability in the way that hearing aids fit, and it appears that critical aspects of the fitting protocol are not always followed. The manufacturer's initials fit algorithm often is an inadequate amplification prescription, sometimes providing less-thanprescribed gain in the high frequencies by as much as $20 \mathrm{~dB}$

Table 2. Comparison of the three organizations

\begin{tabular}{|c|c|c|c|}
\hline & AAA & ASHA & Healthy hearing \\
\hline Advantages & $\begin{array}{l}\text { - From diagnosis to rehabilitation, } \\
\text { patients choose a professional for } \\
\text { each stage. } \\
\text { - Patients can access a } \\
\text { rehabilitation service after wearing } \\
\text { the hearing aid via this web } \\
\text { search. } \\
\text { - In the last stage, MapQuest } \\
\text { provides directions from the user's } \\
\text { location to the clinic. }\end{array}$ & $\begin{array}{l}\text { - When patients type their own } \\
\text { information, they find the best } \\
\text { professionals and clinics. } \\
\text { - There are many certified } \\
\text { professionals which are registered } \\
\text { and undergo continuing } \\
\text { education through the ASHA. }\end{array}$ & $\begin{array}{l}\text { - Large map of the United State } \\
\text { allows the patients to visually find } \\
\text { the professional centers. } \\
\text { - The patients are able to sort } \\
\text { the clinic by rating, distance, } \\
\text { recommendation consequently, } \\
\text { can make a more informed } \\
\text { choice. }\end{array}$ \\
\hline Disadvantages & $\begin{array}{l}\text { - Patients need to type or search } \\
\text { near location. } \\
\text { - For selection of specialty, there } \\
\text { are many professional words } \\
\text { which unexperienced patients are } \\
\text { not familiar with. }\end{array}$ & $\begin{array}{l}\text { - If patients are not familiar with } \\
\text { web search in each stage, they } \\
\text { get confused. } \\
\text { - Although there is information } \\
\text { of the clinic and its employed } \\
\text { professionals, map service does } \\
\text { not provide. }\end{array}$ & $\begin{array}{l}\text { - There is no choice of age or } \\
\text { desired clinic service. Thus, the } \\
\text { patients have a large group of } \\
\text { professionals near their location. }\end{array}$ \\
\hline
\end{tabular}

AAA: American Academy of Audiology, ASHA: American Speech-Language-Hearing Association

118 J Audiol Otol 2016;20(2):114-119 
[12]. Although the greatest advantage of digital hearing aid technology is the flexibility in programming the sound quality and many other electro-acoustic characteristics of the hearing aids highly sophisticated, the computer software that is used to program the hearing aids is getting stick to ask the audiologists their specialty as years go by. Audiologists need to assess patients' hearing difficulties in several ways and define individual goals for them since speech perceptual ability and benefits from hearing aids are highly individualized. After a professional evaluation, the patients can hear many of the changes and actually report high satisfaction with their audiological treatment and services. Again, we expect professional organizations to adopt this system as soon as possible and link hearing-impaired patients with professional audiologists in Korea.

\section{Acknowledgments}

This research was completed while being supported by Brain Korea 21 Plus of National Research Foundation of Korea.

\section{Conflicts of interest}

The authors have no financial conflicts of interest.

\section{REFERENCES}

1) World Health Organization. Deafness and hearing loss, Fact Sheet No300 [cited 2016 Jan 17]. Available from: http://www.who.int/mediacentre/factsheets/fs300/en.

2) Ministry of Health and Welfare. 2014 survey on impaired people [cited 2016 Jan 25]. Available from: http://www.gyotong.org/home/ 2012/bbs/board.php?bo_table $=$ menu79\&wr_id $=2622$.

3) World Health Organization. 1.1 billion people at risk of hearing loss [cited 2016 Jan 7]. Available from: http://www.who.int/mediacentre/ news/releases/2015/ear-care/en.

4) Muzet A. Environmental noise, sleep and health. Sleep Med Rev 2007;11:135-42.

5) Shim HJ. Noise-induced hearing. Hanyang Med Rev 2015;35:84-91.

6) Kim JS, Lee BS. Hearing status of the Korean adults: according to the Fourth Korea National Health and Nutrition Examination Survey 2009. J Korean Public Health Nurs 2011;25:197-208.

7) Statistics Korea. The population condition and prospect of the world and the Korea [cited 2016 Jan 22]. Available from: http://www.moneyweek.co.kr/news/mwView.php?no=2015071116438079103.

8) American Speech-Language-Hearing Association. Executive summary for JCIH Year 2007 position statement: principles and guidelines for early hearing detection and intervention programs [cited 2008 Mar 21]. Available from: http://www.asha.org/uploadedFiles/JCIHExecutive-Summary.pdf.

9) World Health Organization. New born and infant hearing screening [cited 2016 Jan 25]. Available from: http://www.who.int/blindness/ publications/Newborn_and_Infant_Hearing_Screening_Report.pdf.

10) Ministry of Health and Welfare. The first plan of fundamental policies on children [cited 2016 Jan 23]. Available from: http://www.mohw. go.kr/front_new/al/sal0301vw.jsp?PAR_MENU_ID $=04 \& M E N U$ 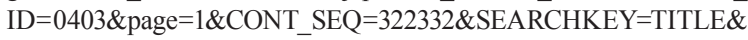 SEARCHVALUE $=$ 아동정책.

11) Ministry of Health and Welfare. Blood sugar management for patients with diabetes and expanded support of health insurance on handicapped people's assistive devices [cited 2016 Jan 21]. Available from: https://www.mohw.go.kr/front_new/al/sal0301vw.jsp?PAR MENU_ID $=04 \& M E N U \_I D=0403 \&$ CONT_SEQ $=327370$.

12) Kochkin S, Beck DL, Christensen LA, Compton-Conley C, Fligor BJ, Kricos PB, et al. MarkeTrak VIII: The impact of the hearing healthcare professional on hearing aid user success. Hear Rev 2010; 17:12-34.

13) Park SG, Yu CM, Chung CH, Kim MK, Huh MJ. A study on the perception of hearing aids according to hearing loss degree for the elderly in Busan. J Speech Lang Hear Disord 2012;21:227-41.

14) Moon SK, Lee JW, Choung YH, Park KH. Clinical analysis of hearing aid failure. J Otolaryngol-Head Neck Surg 2005;48:13-7. 